\title{
Geographic variation in volumetric breast density between screening regions in the Netherlands
}

\author{
Daniëlle van der Waal ${ }^{1}$ • Marleen J. Emaus ${ }^{2}$ - Marije F. Bakker ${ }^{2}$. \\ Gerard J. den Heeten ${ }^{3,4}$ • Nico Karssemeijer ${ }^{5}$ Ruud M. Pijnappel $^{3,6}$. \\ Wouter B. Veldhuis ${ }^{6}$ • André L. M. Verbeek ${ }^{1}$. Carla H van Gils ${ }^{2}$. \\ Mireille J. M. Broeders ${ }^{1,3}$
}

Received: 19 November 2014 /Revised: 10 March 2015 / Accepted: 25 March 2015 /Published online: 3 July 2015

(C) The Author(s) 2015. This article is published with open access at Springerlink.com

\begin{abstract}
Objectives Differences in breast density between populations may explain part of the variation in regional breast cancer screening performance. This study aimed to determine whether regional differences in breast density distribution are present in the Dutch screening population.

Methods As part of the DENSE trial, mammographic density was measured using a fully-automated volumetric method. The regions in our study were based on the geographic coverage of 14 reading units representing a large part of the Netherlands. General linear models were used.

Results Four hundred eighty-five thousand and twenty-one screening participants with a median age of 60 years were included (2013-2014). The proportion of women with heterogeneously or extremely dense breasts ranged from $32.5 \%$ to
\end{abstract}

Daniëlle van der Waal

Danielle.vanderWaal@radboudumc.nl

1 Radboud Institute for Health Sciences (Department for Health Evidence, Mailbox 133), Radboud university medical center, PO Box 9101, 6500 HB Nijmegen, The Netherlands

2 Julius Center for Health Sciences and Primary Care, University Medical Center Utrecht, Utrecht, The Netherlands

3 Dutch Reference Centre for Screening, Nijmegen, The Netherlands

4 Department of Radiology, Academic Medical Centre, University of Amsterdam, Amsterdam, The Netherlands

5 Department of Radiology, Radboud university medical center, Nijmegen, The Netherlands

6 Department of Radiology, University Medical Center Utrecht, Utrecht, The Netherlands
$45.7 \%$ between regions. Mean percent dense volume varied between $6.51 \%$ (95\% confidence interval [CI]: 6.46-6.55) and $7.68 \%$ (95\% CI: 7.66-7.71). Age differences could not explain the variation. Socio-economic status (SES) was positively associated with volumetric density in all analyses (low SES: $6.95 \%$ vs. high SES: $7.63 \%$; $p_{\text {trend }}<0.0001$ ), whereas a potential association between urbanisation and breast density only became apparent after SES adjustment.

Conclusion There appears to be geographic variation in mammographic density in the Netherlands, emphasizing the importance of including breast density as parameter in the evaluation of screening performance.

Key Points

- Mammographic density may affect regional breast cancer screening performance.

- Volumetric breast density varies across screening areas.

- SES is positively associated with breast density.

- Implications of volumetric breast density differences need to be studied further.

Keywords Digital mammography · Breast cancer screening · Mammographic density · Socio-economic status .

Urbanisation

$\begin{array}{ll}\text { Abbreviations } \\ \text { SES } & \text { Socio-economic status } \\ \text { VDG } & \text { Volpara density grade } \\ \text { FFDM } & \text { Full-field digital mammography } \\ \text { SFM } & \text { Screen-film mammography } \\ \text { MLO } & \text { Mediolateral oblique } \\ \text { CC } & \text { Craniocaudal } \\ \text { \%DV } & \text { Percent dense volume } \\ \text { DV } & \text { Dense volume }\end{array}$




\section{Introduction}

Mammographic interpretations are influenced by the distribution of fibroglandular and adipose tissue in the breast. More fibroglandular tissue, i.e., a higher mammographic density, is associated with both an increased breast cancer risk and a decreased sensitivity of mammography [1-3]. Due to the radiation attenuation characteristics of this tissue, tumour masses could be masked on a mammogram [1]. This results in a greater risk of breast carcinomas remaining undetected.

Since breast density will affect breast cancer screening performance, it is important to be aware of differences in mammographic density distribution between the coverage areas of screening radiology groups. Previous screening evaluation studies revealed differences in breast cancer detection rates across the Netherlands $[4,5]$. The extent to which variation in breast density has contributed to these differences has not yet been determined. The average radiologist reads 13,000 mammograms per year, but breast density is not taken into account in the evaluation of this high-volume reading. Objective density measurements are needed for a definitive answer on the magnitude of the geographic differences and the resulting effect on screening performance. Furthermore, the geographic distribution of breast density may provide more insight into differential breast cancer risk.

The Dutch breast cancer-screening programme started in 1989. Until now, geographic comparisons of mammographic density were not possible due to the lack of structural breast density assessments. As part of the DENSE trial, the volumetric breast density distribution could be determined using unprocessed mammogram data collected from screening units throughout the country [6]. Although this is, to our knowledge, the first study to address the geographic variation in volumetric breast density within a national screening programme, a few studies have reported on the association of geographic (e.g., urbanisation level) and demographic (e.g., socio-economic status [SES]) characteristics with breast density [7-11]. These factors may help clarify differences between screening areas, but the previous results have been somewhat inconsistent. A positive association of breast density with SES $[7,9,11]$ and urbanisation $[8,10]$ has been suggested, although disagreement exists on the strength of the associations.

With this study, we want to contribute to the discussion on measuring breast density in national screening programmes. Breast density should only be included as a parameter in a screening evaluation if there is evidence of geographic differences in breast density. The aim of this study was, therefore, to determine whether regional differences in volumetric breast density are present in the Netherlands. In addition, we studied the association of breast density with SES and urbanisation.

\section{Methods}

\section{Study population and data collection}

Women aged 50-75 years are invited biennially for breast cancer screening in the Netherlands. They receive their first invitation in the year they turn 50 or 51 years old. This programme has a full national coverage, with relatively high attendance (79.6 \% in 2012) compared to other European programmes $[5,12]$. Phased installation of density software on servers in screening units of the Dutch programme started in January 2013. Examinations performed at these units between implementation and February 2014 were included in our study. In the Netherlands, screening examinations are read by different radiology groups (hereinafter referred to as reading units) across the country. Mammographic data are centrally stored in a national database and, depending on the screening unit location $\left(n_{\text {total }}=77 ; 57\right.$ mobile, 22 fixed), distributed to specific reading units. The 14 reading units in our study (out of 16 nationwide), therefore, all have different coverage areas, with minimal overlap. Together, they cover a substantial part of the most densely populated areas of the Netherlands, with four out of five screening regions participating in this study. To improve readability of the results, the reading units were numbered, but this does not match the previously used coding in the literature $[4,5]$. The name of each reading unit (based on its location) is described below Table 3, with the corresponding Dutch provinces they (partly) cover in brackets.

As part of the DENSE trial, breast density profiles of participants at enrolled screening units were estimated using unprocessed digital mammogram data. The DENSE trial (NCT01315015) has been described elsewhere [6]. In short, DENSE investigates the (cost-) effectiveness of screening with mammography and MRI, compared to mammography alone in Dutch breast cancer screening participants with extremely dense breasts (BI-RADS density 4/d).

Data on age at screening and four-digit postal codes were obtained for all those being screened. Screening participants are informed about the potential use of screening data in research aimed to improve the programme. Based on Dutch law, medical ethics approval was not needed because anonymized data were used for this study.

\section{SES and urbanisation}

The Netherlands Institute for Social Research (Sociaal en Cultureel Planbureau; SCP) has provided a measure of SES, which combines educational level, income, and labour market position [13]. The SCP collected information on SES by interviewing one person in every six-digit postal code area between 2006 and 2010. This information was then combined to give one score for every four-digit postal code area. The scores were linked to the postal codes in our dataset. 
Degree of urbanisation is based on the number of addresses per square kilometre. Statistics Netherlands has published a five-level categorical scale, with less than 500 addresses at the lowest and more than 2500 addresses at the highest urbanisation level $[14,15]$. The urbanisation degree can be retrieved for each neighbourhood in the Netherlands. The postal codes of these neighbourhoods were matched to the postal codes of the participants.

\section{Mammographic density}

Since the nationwide implementation of full-field digital mammography (FFDM) was completed in 2010, all screening examinations in our study were performed digitally using Selenia systems (Hologic, Bedford, USA). Breast density was determined using Volpara Imaging Software (version 1.5) (Mātakina, Wellington, New Zealand). This FDA-approved software calculates total breast volume (in $\mathrm{cm}^{3}$ ), fibroglandular tissue volume (dense volume [DV]; in $\mathrm{cm}^{3}$ ), fat tissue volume (non-dense volume; in $\mathrm{cm}^{3}$ ), and percentage fibroglandular tissue (percent dense volume [\%DV]) based on the measured Xray attenuation per pixel $[16,17]$. Volpara has developed a categorical scale as an approximation of the BI-RADS density scale: the Volpara Density Grade (VDG). The \%DV is divided into four categories on the VDG-scale (with in brackets the corresponding BI-RADS density): VDG1 $=<4.5 \%$ (almost entirely fatty), VDG2 $=4.5-7.5 \%$ (scattered areas of density), VDG3 $=7.5-15.5 \%$ (heterogeneously dense), and VDG4=> $15.5 \%$ (extremely dense) $[18,19]$. The VDG is based on the mean $\% \mathrm{DV}$ of all views.

The Volpara software version used in the DENSE trial only gives an estimate when both the mediolateral oblique (MLO) and craniocaudal (CC) view are available. The resulting estimate is the average of both. Since a recent policy change (decision made in 2013, officially implemented in 2014), two-view mammography is standard and both views are available for all examinations in the current programme [20]. Directly prior to the policy change, two-view mammography was already widely applied, including in women participating for the first time. Both views were obtained in $99 \%$ of the examinations in the regions included in our study.

In addition, since the difference in density between the left and right view is known to be small, the average of these estimates was used [21]. In this study, the Pearson correlation coefficient for the left and the right view was $0.95,0.91,0.98$, and 0.98 for $\% \mathrm{DV}, \mathrm{DV}$, non-dense volume, and total breast volume, respectively.

\section{Statistical analyses}

A natural logarithmic transformation $[\ln (\mathrm{x}+1)]$ was applied to $\% \mathrm{DV}$ and DV. General linear models were used to calculate geometric means and corresponding $95 \%$ confidence intervals
(CI) of \%DV and DV per reading unit. Furthermore, means of the density measures were calculated for every SES quartile and every urbanisation level. Linear trends were studied with polynomial contrasts. Log-binomial regression was used to study the effect of SES and urbanisation on the VDG. For this analysis, the VDG was dichotomized into VDG1+2 and VDG3+4.

In addition to our main analyses, we performed secondary analyses with two important confounders to provide some insight into the causal association between geographic area and breast density. The first potential confounder included in our models was age at screening. Although the invitation age range is the same in all regions, the age distribution may have varied. Furthermore, dense volume was adjusted for total breast volume. Total breast volume can be seen as a proxy for body-mass index (BMI).

All values were transformed back to the original scale in the tables for ease of interpretation. The statistical tests were two-sided, with a significance level of 0.05 . All analyses were performed using SAS software (version 9.2, SAS Institute).

\section{Results}

A total of 485,021 screening participants were included in our analyses (Table 1). The median age at screening was 60 years (IQR 54-66 years). All density measures are shown in Table 2.

Table 1 Baseline characteristics of the study population $(n=485,021)$

Variables

\begin{tabular}{ll}
\hline & $\begin{array}{l}\text { Median (IQR) } \\
\text { Age (in years) }\end{array}$ \\
& $\% 0(54-66)$ \\
Screening region & \\
Mid-west & $37.0(179,261)$ \\
East & $16.9(81,962)$ \\
South & $21.5(104,198)$ \\
South-west & $24.7(119,600)$ \\
SES & \\
Q1 (lowest SES) & $25.1(121,590)$ \\
Q2 & $24.7(119,810)$ \\
Q3 & $25.1(121,923)$ \\
Q4 (highest SES) & $24.9(120,704)$ \\
Missing & $0.2(994)$ \\
Urbanisation level (addresses/km²) & \\
Very high ( $\geq 2500)$ & $23.2(112,333)$ \\
High (1500-2499) & $31.1(150,813)$ \\
Moderate (1000-1499) & $18.3(88,578)$ \\
Low (500-999) & $16.7(81,185)$ \\
Very low (0-499) & $10.7(52,112)$ \\
\hline
\end{tabular}

$\mathrm{IQR}=$ inter-quartile range, $\mathrm{SES}=$ socio-economic status 
Table 2 Different breast density measures according to age

\begin{tabular}{|c|c|c|c|c|c|c|}
\hline & \multirow[t]{2}{*}{$N$} & \multicolumn{3}{|c|}{ Geometric mean $(95 \% \mathrm{CI})$} & \multicolumn{2}{|l|}{$\%(N)$} \\
\hline & & $\% \mathrm{DV}(\%)$ & $\mathrm{DV}\left(\mathrm{cm}^{3}\right)$ & Total volume $\left(\mathrm{cm}^{3}\right)$ & VDG3 +4 & VDG 4 \\
\hline Total & 485,021 & $7.25(7.25-7.25)$ & $56.97(56.97-56.97)$ & $860.9(859.8-862.1)$ & $40.5(196,312)$ & $7.9(38,330)$ \\
\hline \multicolumn{7}{|l|}{ Age group } \\
\hline$<50 \mathrm{y}^{\mathrm{a}}$ & 13,446 & $9.27(9.20-9.35)$ & $67.33(66.81-67.86)$ & $799.3(792.0-806.6)$ & $60.7(8156)$ & $19.4(2606)$ \\
\hline $50-55$ y & 116,188 & $8.33(8.31-8.35)$ & $62.10(61.94-62.27)$ & $819.9(817.4-822.4)$ & $52.6(61,121)$ & $13.9(16,119)$ \\
\hline $55-60$ y & 105,345 & $7.23(7.21-7.25)$ & $56.22(56.06-56.38)$ & $850.6(847.9-853.3)$ & $41.3(43,549)$ & $7.5(7875)$ \\
\hline $60-65$ y & 96,437 & $6.83(6.81-6.85)$ & $55.29(55.13-55.45)$ & $879.4(876.5-882.2)$ & $36.2(34,912)$ & $5.6(5407)$ \\
\hline $65-70 y$ & 88,258 & $6.61(6.59-6.63)$ & $55.21(55.05-55.38)$ & $902.3(899.3-905.4)$ & $32.7(28,830)$ & $4.4(3922)$ \\
\hline $70-75$ y & 59,405 & $6.47(6.44-6.49)$ & $53.15(52.95-53.35)$ & $883.7(880.0-887.3)$ & $30.4(18,047)$ & $3.7(2200)$ \\
\hline $75 \mathrm{y}^{+}$ & 5942 & $6.34(6.26-6.42)$ & $52.22(51.61-52.83)$ & $883.2(871.7-894.7)$ & $28.1(1670)$ & $3.4(201)$ \\
\hline$p_{\text {trend }}$ & & $<0.0001$ & $<0.0001$ & $<0.0001$ & & \\
\hline
\end{tabular}

$\% \mathrm{DV}=$ percent dense volume, $\mathrm{DV}=$ dense volume, $\mathrm{CI}=$ confidence interval, $\mathrm{VDG}=$ volpara density grade

${ }^{a}$ The time of first invitation is based on location and birth year. Women receive their first invitation in the year they turn 50 or 51 years of age. As a result, a number of women were still 49-years-old at first screening $(\mathrm{n}=13,408)$ and even a few 48 -year-olds were included $(n=38)$

The geometric means of $\% \mathrm{DV}$ and DV were $7.25 \%$ and $56.97 \mathrm{~cm}^{3}$, respectively. The confidence intervals were similar to the mean estimates due to the large sample size. There were 196,312 women (40.5\%) who could be classified as having heterogeneously (VDG3) or extremely (VDG4) dense breasts, with 38,330 women (7.9\%) in the latter category. Age was inversely associated with $\% \mathrm{DV}$ and DV ( $\left.p_{\text {trend }}<0.0001\right)$. The proportion of women with a VDG3/VDG4 classification decreased from $60.7 \%$ in the youngest to $28.1 \%$ in the oldest age group. Total breast volume increased with age $\left(p_{\text {trend }}<\right.$ 0.0001) up until 65-70 years, after which it slightly decreased.

\section{Geographic variation}

Table 3 and Fig. 1 show the geographic variation in breast density in the Netherlands. In the first region (reading unit 1), $32.5 \%$ of the women had heterogeneously (VDG3) or extremely (VDG4) dense breasts. The proportion of women with VDG3/VDG4 in the coverage area of reading unit 14 was $45.7 \%$. The mean \%DV ranged from $6.51 \%(95 \% \mathrm{CI}: 6.46-$ $6.55 \%)$ in the coverage area of reading unit 1 to $7.68 \%(95 \%$ CI: $7.66-7.71 \%$ ) in the coverage area of reading unit 14 . DV ranged from $53.93 \mathrm{~cm}^{3}$ (unit 3; $95 \% \mathrm{CI}: 53.47-54.40 \mathrm{~cm}^{3}$ ) to $59.36 \mathrm{~cm}^{3}$ (unit 6; $95 \% \mathrm{CI}: 59.08-59.65 \mathrm{~cm}^{3}$ ). The geographic variation in mammographic density could not be explained by age differences. Although adjustments for total breast volume did have an effect on DV in some regions, geographic variation in DV still appeared to be present in the fully adjusted model (including age and total breast volume).

\section{Association with SES}

The $\% \mathrm{DV}$ is higher among women with higher SES (mean $\% \mathrm{DV}$ Q1 $=6.95 \%$ vs. Q4=7.63\%; $p_{\text {trend }}<0.0001$ ) (Table 4).
Adjustments for age or urbanisation had little effect on these associations. The positive association between SES and DV only became apparent after adjustment for total breast volume (Table 4). A high SES was also associated with a high VDG (age-adjusted RR Q4 vs. Q1=1.20, 95 \% CI: 1.19-1.21) (Table 5).

\section{Association with urbanisation}

There was minimal evidence of a linear association between urbanisation level and the various density measures (crude mean $\% \mathrm{DV}$ rural $=7.19 \%$ vs. high urbanisation= $7.27 \%$; $p_{\text {trend }}=0.0052$ ) (Table 4$)$. The significant $p_{\text {trend }}$ appeared to be mainly driven by the large numbers and the higher density at the highest urbanisation level, especially in the analyses on DV, whereas the density values appeared to be similar for all other urbanisation levels. When the estimates were additionally adjusted for SES, the positive association between breast density and urbanisation became more pronounced. Similar effects were observed in the analyses with VDG (Table 5). This suggests a confounding role of SES, which was confirmed by the presence of an inverse association between urbanisation level and SES (data not shown).

\section{Discussion}

Our results show that there is geographic variation in volumetric breast density in the Netherlands. Breast density, measured as $\% \mathrm{DV}$ or $\mathrm{DV}$, varies across the coverage areas of different reading units in the Dutch screening programme. Differences in breast density were also observed for different SES groups, with higher SES being associated to higher breast density. A 


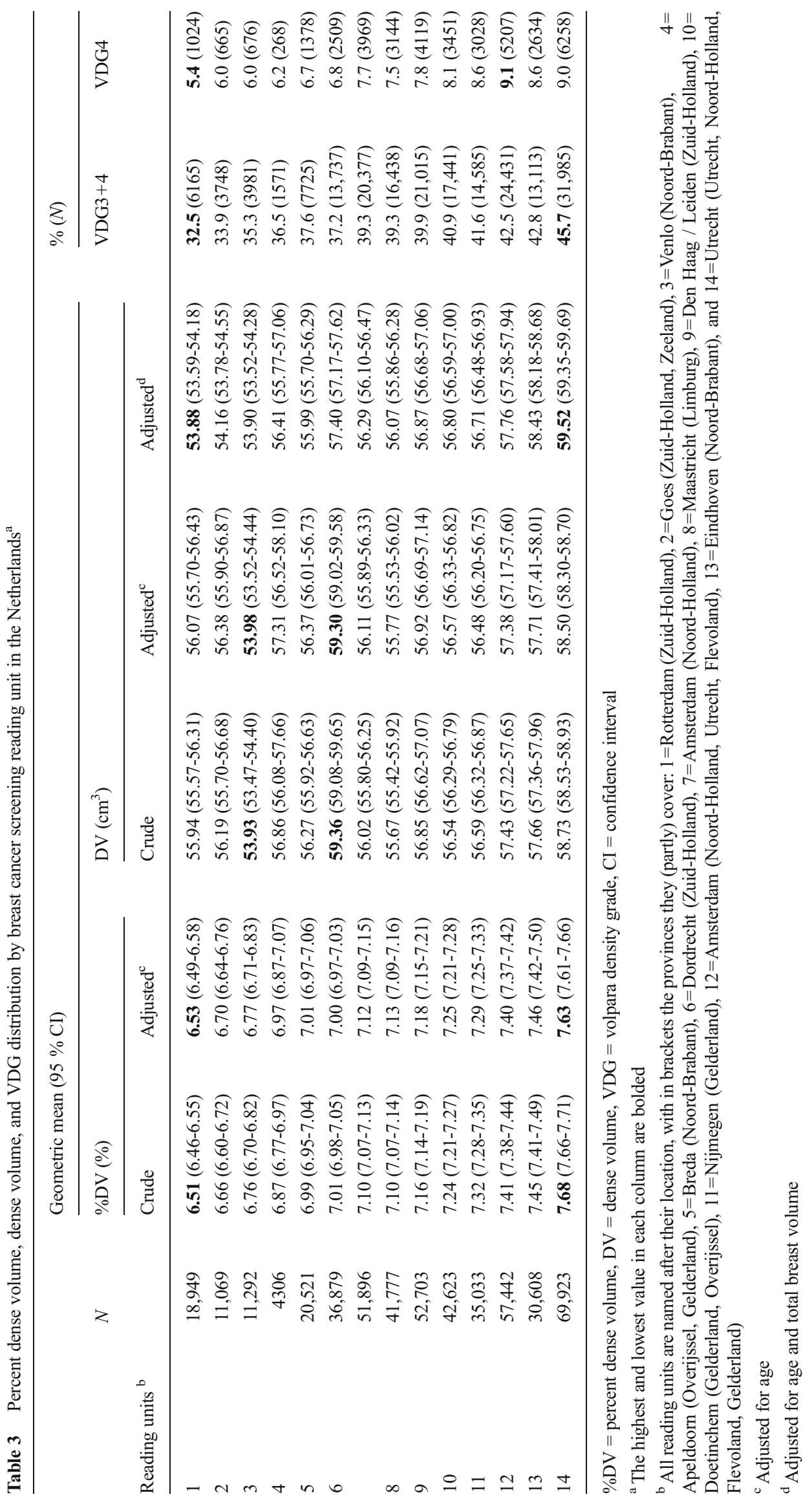


Fig. 1 Age-adjusted geometric means of the percent dense volume across the Netherlands

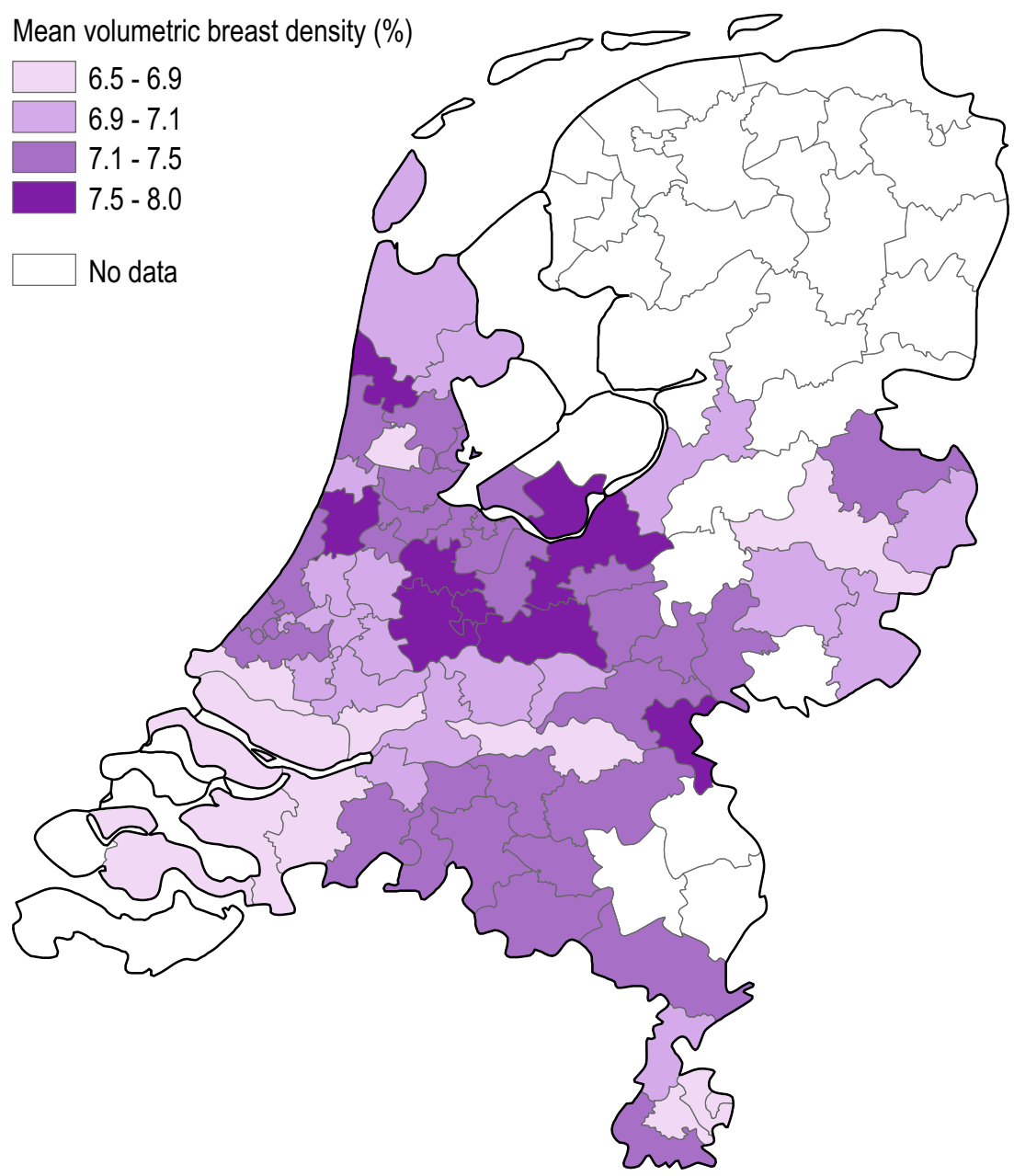

potential positive association with urbanisation level only became apparent after SES adjustments. Differences in age did not explain the observed associations.

In the interpretation of these results, one should take into account that volumetric breast density estimates tend to be lower than estimates obtained with area-based methods (e.g., Cumulus). Consequently, the differences in volumetric density will also tend to be smaller. The observed variation in density may, thus, be associated with a greater difference in breast cancer risk or screening performance than one may intuitively expect based on previous studies involving Cumulus' percent density.

Based on studies with screen-film mammography (SFM), screening performance (e.g., sensitivity and recall rates) can be affected by breast density [22-26]. Preliminary evidence has suggested that FFDM performs better in dense breasts than SFM [27, 28]. Evidence on sensitivity across density categories in FFDM, however, is scarce. Two studies in the US, with annual instead of biennial screening, observed no clear pattern in their secondary analyses on sensitivity within different density categories [29, 30]. However, as mentioned by Kerlikowske et al., missing measurements resulted in limited statistical power and may have introduced bias [29]. In addition, the greater proportion of BI-RADS 0 classifications with FFDM compared with SFM could be associated with high density. Additional imaging in this group may have resulted in a higher screen-detected cancer rate. Finally, adjustments for facility and radiologist effects appeared to reverse the findings. More studies are, thus, still needed on the effect of breast density on FFDM performance in the Netherlands.

Using parameters from SFM studies, however, we can estimate the expected variation in screening performance of the reading units due to differences in breast density distribution. With the performance parameters stratified on BI-RADS density of Yankaskas et al., for example, we can calculate weighted averages (weighted on VDG distributions) to estimate performance (e.g., sensitivity) in each reading unit in our study [26]. Using these parameters, a small amount of the performance variation could be explained by breast density differences in our population, with sensitivity ranging between 76.9-80.3 \% across reading units (range recall rate: 53.959.7 per 1000; range cancer detection: 3.28-3.34 per 1000). Overall estimates of screening performance in the US are, however, very different from the overall Dutch estimates (in 


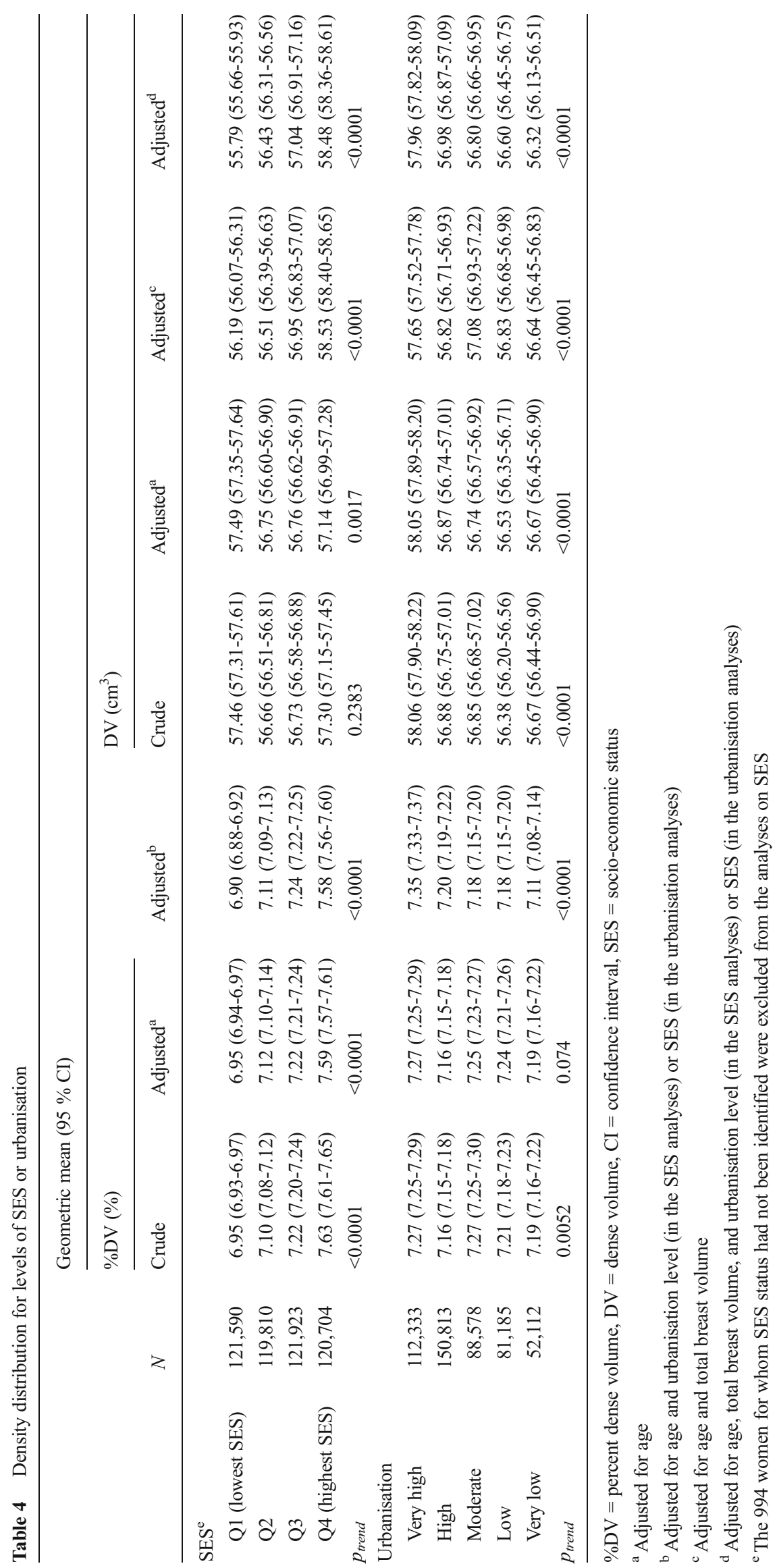


Table 5 Volpara Density Grade for levels of SES or urbanisation

\begin{tabular}{|c|c|c|c|c|c|}
\hline & \multicolumn{2}{|l|}{$\%(N)$} & \multicolumn{3}{|l|}{$\mathrm{RR}^{\mathrm{a}}(95 \% \mathrm{CI})$} \\
\hline & VDG3 +4 & VDG4 & Crude & Adjusted $^{\mathrm{c}}$ & Adjusted $^{\mathrm{d}}$ \\
\hline \multicolumn{6}{|l|}{$\mathrm{SES}^{\mathrm{b}}$} \\
\hline Q1 (lowest SES) & $37.0(45,033)$ & $6.9(8377)$ & 1.00 (Ref.) & 1.00 (Ref.) & 1.00 (Ref.) \\
\hline Q2 & $39.1(46,864)$ & $7.3(8720)$ & $1.06(1.05-1.07)$ & $1.06(1.05-1.07)$ & $1.07(1.06-1.08)$ \\
\hline Q3 & $40.5(49,419)$ & 7.9 (9592) & $1.09(1.08-1.11)$ & $1.09(1.08-1.10)$ & $1.11(1.10-1.12)$ \\
\hline Q4 (highest SES) & $45.2(54,563)$ & $9.6(11,555)$ & $1.22(1.21-1.23)$ & $1.20(1.19-1.21)$ & $1.22(1.21-1.23)$ \\
\hline \multicolumn{6}{|l|}{ Urbanisation } \\
\hline Very high & $40.7(45,703)$ & $8.4(9469)$ & 1.00 (Ref.) & 1.00 (Ref.) & 1.00 (Ref.) \\
\hline High & $39.9(60,227)$ & $7.6(11,467)$ & $0.98(0.97-0.99)$ & $0.98(0.97-0.99)$ & $0.97(0.96-0.98)$ \\
\hline Moderately high & $41.2(36,530)$ & $7.9(7034)$ & $1.01(1.00-1.02)$ & $1.01(1.00-1.02)$ & $0.96(0.95-0.97)$ \\
\hline Low & $40.4(32,834)$ & $7.8(6367)$ & $0.99(0.98-1.01)$ & $1.00(0.99-1.01)$ & $0.96(0.95-0.97)$ \\
\hline Very low & $40.3(21,018)$ & 7.7 (3993) & $0.99(0.98-1.00)$ & $0.99(0.98-1.01)$ & $0.95(0.93-0.96)$ \\
\hline
\end{tabular}

$\mathrm{SES}=$ socio-economic status, $\mathrm{RR}=$ risk ratio, $\mathrm{CI}=$ confidence interval, $\mathrm{VDG}=$ volpara density grade,

${ }^{a}$ These RRs were estimated using log-binomial regression: VDG3 + 4 compared to VDG1+2

${ }^{\mathrm{b}}$ The 994 women for whom SES status had not been identified were excluded from the analyses on SES

${ }^{\mathrm{c}}$ Adjusted for age

${ }^{\mathrm{d}}$ Adjusted for age and urbanisation level (in the SES analyses) or SES (in the urbanisation analyses)

2011: recall $=21.4$ per 1000 ; cancer detection $=6.2$ per 1000) [5]. The effect of density on screening performance in the Netherlands, thus, still needs to be assessed.

Breast density is also associated with breast cancer risk $[1,3,31]$. Indeed, a similar gradient in breast cancer incidence appeared to exist across the country [32]. Since we focused on the effect of density on screening practice, no information on other risk factors was collected. Differential screening attendance may have contributed to the variation in volumetric breast density. Both SES and urbanisation are factors that could be associated with attendance. When we included these factors in the regional analyses, the observed variation in volumetric breast density slightly decreased (data not shown). The remaining differences would have to be attributed to unmeasured or even unknown confounders. Aetiological inferences on differences in \%DV are hindered by the absence of information on BMI. Because DV is expected to be less affected by BMI confounding, based on a meta-analysis involving dense area [33], the observed differences in DV do indicate that variation in dense tissue is present that may translate into a difference in breast cancer risk. Further studies are needed to confirm this result.

A study on four widely dispersed geographic areas showed that differences in breast density could be explained by wellknown confounders, including reproductive behaviour [34]. Other studies on breast density have corrected for use of hormone replacement therapy (HRT). Only $13 \%$ of Dutch women (49-70 years) used HRT in the 1990s [35], and the percentage is expected to be even lower since the publication of the Million Women Study on the adverse effects of HRT [36].
Based on the low HRT-use, this risk factor is not expected to have had a significant effect here.

To get more insight into the geographic differences, we further studied SES and urbanisation. A (weak) positive association between SES and breast density has been observed before $[7,9,11]$. Despite the differences in setting (e.g., country) and definitions (both SES and density), these results appear to be consistent with our observations. Potential explanatory factors include differences in BMI and reproductive behaviour. If a high $\mathrm{BMI}$ is associated with a low $\% \mathrm{DV}$ and a low SES, then the differences in \%DV between SES groups could be explained by variation in BMI. In contrast, based on the positive correlation between BMI and DV observed in previous studies, BMI adjustment is only expected to increase variation in DV [37, 38]. This was supported by the results from our models including total breast volume (a BMI-proxy).

A linear association between urbanisation and breast density became apparent after SES adjustment. In general, the results were somewhat suggestive of an increased density at the highest urbanisation level. Two previous studies involving urbanisation and BI-RADS density found a positive association $[8,10]$. Both authors described a potential link with exposure to environmental factors. Aitken et al., on the other hand, did not observe an association between a dichotomous rural/urban measure and breast density [7].

One of the limitations of our study is that we used measures at area level (i.e., postal codes) instead of individual level (like educational level) for both urbanisation and SES, which may have led to misclassification. However, we expect the misclassification to be independent of outcome (high/low volumetric 
density). Although the suggestion that this can only lead to attenuation of the true effect does not always hold [39], we deem it unlikely that the observed effect can be explained entirely by misclassification. An analysis with SES as a continuous variable appeared to confirm the positive trend (data not shown). Furthermore, previous studies have shown that area-based measures give a good approximation of individual SES [40]. Another limitation is the fact that the $\mathrm{CC}$ views tend to be missing more often for women with fatty breasts and these lower density values were, thus, not included in our dataset, although the overall number of missing CCs was small (1\%). When we limited the analyses to a period with $100 \%$ available $\mathrm{CC}$ views, the three reading units with the highest density remained at the top and the overall difference with the low breast density units was similar. Small differences can be explained by slight fluctuations in the invited populations over time.

Strengths include the automated volumetric density measurements. The lack of intra- or interobserver variability enables comparison of different reading units. Studies using qualitative measures would be affected by differences in density assessment behaviour of radiologists [41]. In addition, there is limited variation in technology, methodology, and training in the Dutch screening programme, which could otherwise have confounded the results. Finally, the large study population is expected to be representative of the Dutch screened population, as women from all SES classes have access to high-quality screening.

In conclusion, differences in breast density between regions in the Netherlands have been established in this study. Geographic variation in breast density is likely to be present in other countries as well. Due to limited evidence on the association between volumetric density and screening performance, the clinical implications of these differences remain to be further elucidated. This will help move the discussion on routine breast density measurements in screening forward. Provided that there is an adequate infrastructure regarding the storage of unprocessed mammogram data, automated software programs could potentially be used to obtain reproducible breast density measurements within national screening programmes.

Acknowledgments The authors would like to thank the regional screening organisations, Matakina, Dutch Reference Centre for Screening and the National Institute for Public Health and the Environment for their advice and in-kind contributions for organizing the breast density assessments. In addition, the authors thank the screening organisations (Foundation of Population Screening East, Foundation of Population Screening Mid-West and Foundation of Population Screening South, Foundation of Population Screening South-West) for providing the data and Henriette Giesbers for making Fig. 1.

The scientific guarantor of this publication is M.J.M. Broeders. The authors of this manuscript declare relationships with the following company: Matakina (G. den Heeten: former member of the medical advisory board, N. Karssemeijer: co-founder, shareholder and scientific advisor). The authors state that this work has not received any funding. However, the DENSE trial is financially supported by the University Medical Center Utrecht (UMC Utrecht, Project number: UMCU DENSE), the Netherlands Organization for Health Research and Development (ZonMw, Project number: ZONMW-200320002-UMCU), the Dutch Cancer Society (KWF Kankerbestrijding, Project numbers: DCS-UU2009-4348 and UU-2014-6859), the Dutch Pink Ribbon / a Sister's hope (Project number: Pink Ribbon-10074), Bayer HealthCare, Medical Care (Project number: BSP-DENSE), and Stichting Kankerpreventie MiddenWest. For research purposes, Matakina (Wellington, New Zealand) has provided Volpara Imaging Software 1.5 for installation on servers in the screening units of the Dutch screening program. No complex statistical methods were necessary for this paper. Institutional Review Board approval was not obtained because medical ethics approval is not needed for this type of study, with no extra burden for participants and anonymized data, according to the Dutch law. Written informed consent was not required for this study because the data were obtained in the context of an agreement between the regional screening organisations and the Dutch Reference Centre for Screening. Women automatically consent to the use of their data for scientific purposes by participating in screening. The screening organisations are responsible for data delivery in accordance with privacy regulations, particularly regarding anonymizing data and potentially removing data of participants who objected to the exchange of personal data with specific organisations (opt-out procedure). Methodology: cross sectional multicenter study.

Open Access This article is distributed under the terms of the Creative Commons Attribution-NonCommercial 4.0 International License (http:// creativecommons.org/licenses/by-nc/4.0/), which permits any noncommercial use, distribution, and reproduction in any medium, provided you give appropriate credit to the original author(s) and the source, provide a link to the Creative Commons license, and indicate if changes were made.

\section{References}

1. Boyd NF, Guo H, Martin LJ et al (2007) Mammographic density and the risk and detection of breast cancer. N Engl J Med 356:227236

2. Kerlikowske K (2007) The mammogram that cried Wolfe. N Engl J Med 356:297-300

3. McCormack VA, dos Santos Silva I (2006) Breast density and parenchymal patterns as markers of breast cancer risk: a meta-analysis. Cancer Epidemiol Biomarkers Prev 15:1159-1169

4. National Evaluation Team for Breast Cancer Screening (NETB) (2009) National evaluation of breast cancer screening in the Netherlands, 1990-2007. NETB, Rotterdam

5. National Evaluation Team for Breast Cancer Screening (NETB) (2014) National evaluation of breast cancer screening in the Netherlands 1990-2011/2012. NETB, Rotterdam

6. Breast cancer screening with MRI in women aged 50-75 years with extremely dense breast tissue: the DENSE Trial. Available via http://clinicaltrials.gov/show/NCT01315015. Accessed 17 Jul 2014

7. Aitken Z, Walker K, Stegeman BH et al (2010) Mammographic density and markers of socioeconomic status: a cross-sectional study. BMC Cancer 10:35

8. Perry NM, Allgood PC, Milner SE, Mokbel K, Duffy SW (2008) Mammographic breast density by area of residence: possible evidence of higher density in urban areas. Curr Med Res Opin 24:365368

9. Vachon CM, Kuni CC, Anderson K, Anderson VE, Sellers TA (2000) Association of mammographically defined percent breast density with epidemiologic risk factors for breast cancer (United States). Cancer Causes Control 11:653-662 
10. Viel JF, Rymzhanova R (2012) Mammographic density and urbanization: a population-based screening study. J Med Screen 19:20-25

11. Samuels L, Astley SM, Maxwell A et al (2013) Relationship between volumetric breast density and socioeconomic status. Breast Cancer Res 15:P21

12. Giordano L, von Karsa L, Tomatis M et al (2012) Mammographic screening programmes in Europe: organization, coverage and participation. J Med Screen 19:72-82

13. Knol F (1998) Van hoog naar laag, van laag naar hoog: de sociaalruimtelijke ontwikkeling van wijken tussen 1971-1995 [From high to low, from low to high: The social-spatial development of districts between 1971 to 1995]. Sociaal en Cultureel Planbureau, The Hague

14. den Dulk CJ, van de Stadt H, Vliegen JM (1992) Een nieuwe maatstaaf voor stedelijkheid: de omgevingsadressendichtheid [A new measure for degree of urbanisation: the address density of the surrounding area]. Maandstatistiek van de bevolking 40:14-27

15. Statistics Netherlands. Available via http://www.cbs.nl/en-GB/ $\mathrm{menu} / \mathrm{methoden} /$ begrippen/default.htm? ConceptID $=658$. Accessed 17 Jul 2014

16. Highnam R, Brady M (1999) Mammographic image analysis. Kluwer Academic, Dordrecht

17. van Engeland S, Snoeren PR, Huisman H, Boetes C, Karssemeijer $\mathrm{N}$ (2006) Volumetric breast density estimation from full-field digital mammograms. IEEE Trans Med Imaging 25:273-282

18. Sickles EA, D’Orsi CJ, Bassett LW et al (2013) ACR BI-RADS ${ }^{\circledR}$ Mammography. In: ACR BI-RADS ${ }^{\circledR}$ Atlas, breast imaging reporting and data system. American College of Radiology, Reston

19. Highnam R, Brady M, Yaffe M, Karssemeijer N, Harvey J (2010) Robust breast composition measures - Volpara. International Workshop on Digital Mammography 2010. Springer-Verlag, Girona

20. Health Council of the Netherlands (2013) Population Screening Act: mammography in two directions as standard. Health Council of the Netherlands, The Hague

21. Byng JW, Boyd NF, Little L et al (1996) Symmetry of projection in the quantitative analysis of mammographic images. Eur J Cancer Prev 5:319-327

22. Carney PA, Miglioretti DL, Yankaskas BC et al (2003) Individual and combined effects of age, breast density, and hormone replacement therapy use on the accuracy of screening mammography. Ann Intern Med 138:168-175

23. Kolb TM, Lichy J, Newhouse JH (2002) Comparison of the performance of screening mammography, physical examination, and breast US and evaluation of factors that influence them: an analysis of 27,825 patient evaluations. Radiology 225:165-175

24. Mandelson MT, Oestreicher N, Porter PL et al (2000) Breast density as a predictor of mammographic detection: comparison of intervaland screen-detected cancers. J Natl Cancer Inst 92:1081-1087

25. van Gils $\mathrm{CH}$, Otten JD, Verbeek AL, Hendriks JH, Holland R (1998) Effect of mammographic breast density on breast cancer screening performance: a study in Nijmegen, The Netherlands. J Epidemiol Community Health 52:267-271

26. Yankaskas BC, Cleveland RJ, Schell MJ, Kozar R (2001) Association of recall rates with sensitivity and positive predictive values of screening mammography. AJR Am J Roentgenol 177: $543-549$
27. Al Mousa DS, Ryan EA, Mello-Thoms C, Brennan PC (2014) What effect does mammographic breast density have on lesion detection in digital mammography? Clin Radiol 69:333-341

28. Souza FH, Wendland EM, Rosa MI, Polanczyk CA (2013) Is fullfield digital mammography more accurate than screen-film mammography in overall population screening? A systematic review and meta-analysis. Breast 22:217-224

29. Kerlikowske K, Hubbard RA, Miglioretti DL et al (2011) Comparative effectiveness of digital versus film-screen mammography in community practice in the United States: a cohort study. Ann Intern Med 155:493-502

30. Pisano ED, Gatsonis C, Hendrick E et al (2005) Diagnostic performance of digital versus film mammography for breast-cancer screening. N Engl J Med 353:1773-1783

31. Varghese JS, Thompson DJ, Michailidou K et al (2012) Mammographic breast density and breast cancer: evidence of a shared genetic basis. Cancer Res 72:1478-1484

32. den Hertog FRJ, Dijk BAC, Luth TK (2011) Aantal invasieve borsttumoren 2006-2009 [Number of invasive breast tumours 2006-2009]. In: Volksgezondheid Toekomst Verkenning, Nationale Atlas Volksgezondheid. RIVM, Bilthoven

33. Pettersson A, Graff RE, Ursin G et al (2014) Mammographic density phenotypes and risk of breast cancer: a meta-analysis. J Natl Cancer Inst 106, dju078. doi:10.1093/jnci/dju078

34. Maskarinec G, Pagano I, Chen Z, Nagata C, Gram IT (2007) Ethnic and geographic differences in mammographic density and their association with breast cancer incidence. Breast Cancer Res Treat $104: 47-56$

35. van Duijnhoven FJ, van Gils CH, Bezemer ID, Peeters PH, van der Schouw YT, Grobbee DE (2006) Use of hormones in the menopausal transition period in the Netherlands between 1993 and 1997. Maturitas 53:462-475

36. Beral V, Million Women Study Collaborators (2003) Breast cancer and hormone-replacement therapy in the Million Women Study. Lancet 362:419-427

37. Lokate M, Kallenberg MG, Karssemeijer N, Van den Bosch MA, Peeters PH, Van Gils CH (2010) Volumetric breast density from full-field digital mammograms and its association with breast cancer risk factors: a comparison with a threshold method. Cancer Epidemiol Biomarkers Prev 19:3096-3105

38. Schetter SE, Hartman TJ, Liao J et al (2014) Differential impact of body mass index on absolute and percent breast density: implications regarding their use as breast cancer risk biomarkers. Breast Cancer Res Treat 146:355-363

39. Rothman KJ, Greenland S, Lash TL (2008) Validity in epidemiologic studies. In: Rothman KJ, Greenland S, Lash TL (eds) Modern epidemiology, 3rd edn. Lippincott Williams \& Wilkins, Philadelphia, pp 128-147

40. Smits J, Keij I, Westert G (2001) Effecten van sociaal-economische status van kleine, middelgrote en grote geografische eenheden op de sterfte [Effects of socio-economic status of small, average and large geographic units on mortality]. Maandstatistiek van de bevolking 49:4-10

41. Ciatto S, Houssami N, Apruzzese A et al (2005) Categorizing breast mammographic density: intra- and interobserver reproducibility of BI-RADS density categories. Breast 14:269-275 